\title{
The Myomodulin-related Neuropeptides: Characterization of a Gene Encoding a Family of Peptide Cotransmitters in Aplysia
}

\author{
M. W. Miller, ${ }^{1,2,3, a}$ S. Beushausen, ${ }^{4}$ A. Vitek, ${ }^{2}$ S. Stamm, ${ }^{3}$ I. Kupfermann, ${ }^{1,5}$ J. Brosius, ${ }^{3}$ and K. R. Weiss ${ }^{2,3}$ \\ ${ }^{1}$ Center for Neurobiology and Behavior, The New York State Psychiatric Institute, New York, New York 10032 , \\ 2Department of Physiology and Biophysics and ${ }^{3}$ Fishberg Research Center for Neurobiology, Mount Sinai School of \\ Medicine, New York, New York 10029, 4Laboratory of Neurobiology, NINDS, Bethesda, Maryland 20892, and ${ }^{5}$ Department \\ of Physiology and Cellular Biophysics, Columbia University, College of Physicians and Surgeons, New York, New York \\ 10032
}

The myomodulin-related peptides comprise a family of cotransmitters that modulate neuromuscular signaling in the feeding system of Aplysia. In this study, cDNA clones encoding a myomodulin precursor polypeptide were isolated and characterized. This precursor contains seven different myomodulin-related peptides, one of which, myomodulin A, is present in 10 contiguous copies. The sequence of a myomodulin genomic clone indicates that all of these myomodulin-related peptides are encoded on a single exon. The myomodulin gene is expressed in a tissue-specific manner and myomodulin mRNA is localized to specific neurons in the Aplysia CNS. The presence of multiple related neuropeptides can greatly increase the range and precision of signaling at synapses where they act as modulator cotransmitters.

[Key words: neuropeptide, cotransmitter, precursor, Aplysia californica, myomodulin, neuromodulator, peptide family, polypeptide, mollusk, invertebrate]

The process of neuropeptide biosynthesis, in which multiple structurally related or unrelated peptides are generated from a single precursor polyprotein, serves to expand the spatial and temporal range of neuronal signaling (Herbert et al., 1981; Cropper et al., 1987b, 1991; Gainer, 1988; Sossin et al., 1989). One function for which such an enhanced range of action appears particularly well suited is the modulation of synaptic transmission (Kupfermann, 1979; Kaczmarek and Levitan, 1987). Studies with a number of simplified neuronal and neuromuscular systems from vertcbrates and invertcbrates have been instrumental in characterizing physiological properties of peptidergic synaptic modulation (Jan and Ian, 1982; O'Shea et al., 1985; Bishop et al., 1987; Marder, 1988).

Several neuropeptides act as modulators of neurally evoked contractions in muscles that participate in feeding-related behaviors in Aplysia (Lloyd et al., 1984; Richmond et al., 1986;

\footnotetext{
Received Sept. 4, 1992; revised Jan. 13, 1993; accepted Feb. 11, 1993.

We thank Robert $S$. Woolley for assistance with the figures and Drs. Marc Glucksman, William C. Probst, and Wayne Sossin for reading earlier versions of the manuscript. This study was supported by Grants MH36730 and GM32099 and funds from the McKnight Endowment Fund for Neuroscience.

Correspondence should be addressed to Dr. Mark W. Miller, \%Dr. K. R. Weiss, Department of Physiology and Biophysics, Box 1218, Mount Sinai School of Medicine, 1 Gustave Levy Place, New York, NY 10029.

a Present address: Institute of Neurobiology, University of Puerto Rico, Boulevard del Valle 201, Old San Juan, PR 00901.

Copyright (C) 1993 Society for Neuroscience $0270-6474 / 93 / 133358-10 \$ 05.00 / 0$
}

Cropper et al., 1987a,b, 1988, 1990a, 1991; Church et al., 1991). One such peptide, myomodulin A (Pro-Met-Ser-Met-Leu-ArgLeu- $\mathrm{NH}_{2}$ ), was originally purified from neural elements in the accessory radula closer (ARC) muscle (Cropper et al., 1987b), a muscle utilized in the biting phase of feeding (Cohen et al., 1978; Cropper et al., 1990b). Exogenous application of myomodulin A produces an enhancement of evoked ARC contractions via postsynaptic actions on the muscle (Cropper et al., 1987b, 1991; Brezina et al., 1991; Probst et al., 1992). The demonstrated synthesis of myomodulin A by an identified motor neuron (B16) innervating the ARC (Cropper et al., 1987b), its rapid axonal transport to the ARC (Lloyd, 1988), and the presence of myomodulin-like immunoreactivity in nerve fibers and varicosities on the ARC (Miller et al., 1991a) further support a role of this peptide in neuromuscular signaling. It has been proposed that the motor neuron $\mathrm{B} 16$, in which $\mathrm{ACh}$ acts as the principal neurotransmitter substance (Cohen et al., 1978), utilizes myomodulin A as a modulatory cotransmitter (Cropper et al., 1987b).

Myomodulin A appears to exert multiple actions in diverse neural circuits in Aplysia. Within the feeding circuit, additional motor neurons synthesize myomodulin A (Church and Lloyd, 1991) and it has been shown that the peptide has modulatory effects on a class of cerebral mechanosensory neurons $\left(C M-S_{B}\right.$ cells; Rosen et al., 1989). A high level of transport from the cerebral to the buccal ganglion further suggests that myomodulin $A$ is involved in the central regulation of feeding-related behaviors (Lloyd, 1988). Myomodulin-like immunoreactive material is widespread throughout the Aplysia nervous system, occurring in specific cell bodies and clusters in each of the central ganglia and in fibers in each of the connectives (Miller et al., 1991a). Exogenous application of myomodulin A produces a hyperpolarization of cells of the left upper quadrant (LUQ) of the abdominal ganglion (Alevizos et al., 1987) and can reverse increases in excitability and spike duration produced by 5 -HT in tail sensory neurons of the pleural ganglion (Critz et al., 1989). Myomodulin-immunoreactive fibers and varicosities are present on peripheral tissues associated with the reproductive, digestive, and circulatory systems (Miller et al., 1991a).

Recent findings indicate that myomodulin $\mathrm{A}$ belongs to a family of related neuropeptides that modulate contraction of feeding muscles in a variety of mollusks. A structurally similar octapeptide, termed myomodulin B (Gly-Ser-Tyr-Arg-Met-MetArg-Leu- $\mathrm{NH}_{2}$ ), was purified from the ARC of Aplysia and found 
to modulate evoked ARC contractions (Cropper et al., 1991). Myomodulin A and a related heptapeptide, termed Fusinus myomodulin (Pro-Met-Asn-Met-Leu-Arg-Leu- $\mathrm{NH}_{2}$ ), have been purified from the central ganglia of the prosobranch Fusinus ferrigineus and were found to modulate radula muscle contractions (Kobayashi and Muneoka, 1990). Finally, the catch-relaxing peptide (CARP; Ala-Met-Leu-Met-Leu-Arg-Leu-NH ${ }_{2}$ ), isolated from the pedal ganglia of the bivalve Mytilus edulis (Hirata et al., 1987), also modulates evoked contractions of feeding-related muscles of gastropods (Hirata et al., 1989).

In this study, a molecular cloning approach was used in order to provide a more complete characterization of the myomodulin-related peptides in Aplysia.

Some of these findings have been reported previously in abstract form (Miller et al., 1991 b).

\section{Materials and Methods}

Specimens of Aplysia californica were obtained commercially (Marinus, Inc., Long Beach, CA). Standard molecular cloning protocols were followed for most of the experiments (Sambrook et al., 1989).

Isolation of $c D N A$ clones. Six 64-fold degenerate 17-mer oligodeoxynucleotide probes, designed from the amino acid sequence of myomodulin A, were synthesized by the DNA Core Facility, Mount Sinai School of Medicine. The probes differed only in the codon for serine (italicized): CCN ATG TCA ATG YTN MG, CCN ATG TCG ATG YTN MG, CCN ATG TCC ATG YTN MG, CCN ATG TCT ATG YTN MG, CCN ATG $A G C$ ATG YTN MG, and CCN ATG $A G T$ ATG YTN MG $\left(\mathrm{Y}=\mathrm{C}\right.$ or $\mathrm{T} ; \mathrm{M}-\mathrm{C}$ or $\mathrm{A} ; \mathrm{N}-\mathrm{A}, \mathrm{C}, \mathrm{G}$, or $\mathrm{T}$; orientation $5^{\prime}$ to $\left.3^{\prime}\right)$. The oligonucleotides were each end-labeled with $\gamma-{ }^{32}$ P-ATP using T4 polynucleotide kinase. The six probes were pooled for screening duplicate replica filters of $5 \times 10^{5}$ plaque-forming units (pfus) from a $\lambda \mathrm{gt} 10 \mathrm{Aplysia}$ buccal ganglion cDNA library (provided by R. Scheller, Stanford University). Hybridization solution consisted of $5 \times \operatorname{SSC}(0.75 \mathrm{M} \mathrm{NaCl}$, $0.075 \mathrm{~m} \mathrm{Na}$ citrate), $50 \mathrm{~mm} \mathrm{NaP}$ ( $\mathrm{pH} 6.8), 1 \mathrm{~mm}$ sodium pyrophosphate, $5 \times$ Denhardt's solution [Denhardt's solution: $0.2 \%$ Ficoll, $0.2 \%$ bovine serum albumin (BSA), $0.2 \%$ polyvinylpyrrolidone], $20 \%$ formamide, and $100 \mu \mathrm{g} / \mathrm{ml}$ denatured salmon sperm DNA. Filters were hybridized overnight at $40^{\circ} \mathrm{C}$, washed [ $1 \times \mathrm{SSC}, 1 \%$ sodium dodecyl sulfate (SDS); $44^{\circ} \mathrm{C}, 4 \times 20 \mathrm{~min}$ ], and autoradiographed overnight $\left(-80^{\circ} \mathrm{C}\right.$; with Spectroline L Plus intensifying screen). Candidate clones were purified through a tertiary screen.

Nucleotide sequence analysis. Phage inscrts were subcloncd into the plasmid vector pBluescript SK ${ }^{+}$(Stratagene, La Jolla, CA), and the nucleotide sequences of both strands were determined using the chaintermination method (Sanger et al., 1977) on double-stranded template DNA (Sequenase system, U.S. Biochemical, Cleveland, OH). Samples were electrophoretically separated on denaturing gradient polyacrylamide gels. Ambiguities resulting from compressions were resolved using 7-deaza dGTP or dITP according to the directions supplied with the kit.

Polymerase chain reaction (PCR). The order and orientation of clone fragments (see Results) were confirmed by generating a PCR product spanning two internal $E c o$ R I sites. Oligonucleotide primers (positions denoted by arrows in Fig. 1) PMS009 (Fig. 2, nucleotide positions 157173) and PMSO04 (Fig. 2, nucleotide positions 843-859) were used to amplify template DNA from $1 \mu$ of phage stock. PCR was performed in a $50 \mu$ l reaction mixture: $16.6 \mathrm{mM}\left(\mathrm{NH}_{4}\right)_{2} \mathrm{SO}_{4} ; 200 \mu \mathrm{M}$ deoxynucleoside triphosphates (dNTPs; Pharmacia LKB); 67 mм Tris HCl, pH 8.8; $1.5 \mathrm{~mm} \mathrm{MgCl} ; 170 \mu \mathrm{g} / \mathrm{ml}$ bovine serum albumin; $1 \mathrm{U}$ of AmpliTak (Perkin-Elmer); and $200 \mathrm{~nm}$ concentration of each primer. Thirty cycles were used: $30 \mathrm{sec}$ denaturation $\left(94^{\circ} \mathrm{C}\right), 1 \mathrm{~min}$ annealing $\left(50^{\circ} \mathrm{C}\right)$, and 2 min extension $\left(72^{\circ} \mathrm{C}\right.$ ). Products were isolated (Geneclean kit, Bio 101) from a $1 \%$ agarose gel, digested with Hind III and $R s a$ I, and subcloned between EcoR V and Hind III sites of pBluescript (Fig. 1, pMM21), and the sequences of both strands were determined (see above).

DNA blot hybridizations. For Southern blot analyses, genomic DNA was isolated from the ovotestis of a single Aplysia specimen, digested to completion (overnight at $37^{\circ} \mathrm{C}$ ) with selected restriction enzymes, size-fractionated on a $0.8 \%$ agarose gel $(10 \mu \mathrm{g} / \mathrm{lane})$, denatured, and transferred onto nylon membrane (MSI, Westboro, MA). The filter was prehybridized at $42^{\circ} \mathrm{C}$ for $3 \mathrm{hr}$ in $6 \times \mathrm{SSC}, 2.5 \times$ Denhardt's solution (see above), $1.0 \%$ SDS, $10 \%$ dextran sulfate, $35 \%$ formamide, and 100 $\mu \mathrm{g} / \mathrm{ml}$ heat-denatured salmon sperm DNA. Insert DNA [ 550 hase pair (bp)] from a myomodulin clone (Fig. 1, pMM13) was labeled by random hexamer priming (U.S. Biochemical), heat denatured $\left(95^{\circ} \mathrm{C}, 5 \mathrm{~min}\right)$, and hybridized overnight at $42^{\circ} \mathrm{C}$. Blots were washed (final conditions: $0.2 \times$ SSC, $0.2 \% \mathrm{SDS}, 65^{\circ} \mathrm{C}$ ) prior to autoradiography.

RNA blot hybridizations. PolyA ${ }^{+}$-selected RNA was isolated from the central nervous system or the ovotestis, denatured and size fractionated ( $5 \mu \mathrm{g} /$ lane) on a $1.2 \%$ agarose gel, transferred to nylon membrane, and hybridized with insert DNA from pMM13 ${ }^{32} \mathrm{P}$-labeled by random hexamer priming. The hybridization solution contained $5 \times$ SSC, $2.5 \times$ Denhardt's solution, and $100 \mu \mathrm{g} / \mathrm{ml}$ heat-denatured salmon sperm DNA. Blots were washed (final conditions: $0.2 \times \mathrm{SSC}, 0.2 \% \mathrm{SDS}, 42^{\circ} \mathrm{C}$ ) prior to autoradiography.

In situ hybridization. Complementary RNA (cRNA) probes were generated from a cloned $390 \mathrm{bp}$ fragment of the coding region of the myomodulin cDNA (corresponding to bases 294-683 of Fig. 2). The probes were labeled with digoxigenin-11-dUTP according to manufacturer's specifications (Genius Kit, Boehringer Mannheim Biochemicals, Indianapolis, IN). Sections $(10-15 \mu \mathrm{m})$ of the ring ganglia were collected on silanated slides (Clayton and Alvarez-Buylla, 1989), cross-linked using UV light (Tiedge, 1991), treated with proteinase $\mathrm{K}(10 \mu \mathrm{g} / \mathrm{ml}, 5 \mathrm{~min})$, and subjected to postfixation (4\% paraformaldehyde, $5 \mathrm{~min}$ ). Prehybridization $(1-2 \mathrm{hr})$ and hybridization were carried out at $50^{\circ} \mathrm{C}$. Following washes $\left(60^{\circ} \mathrm{C}, 2 \times \mathrm{SSC}\right.$ ) and RNAse treatment (RNase A, $25 \mu \mathrm{g} /$ liter, $37^{\circ} \mathrm{C}$ ), $1 \mathrm{hr}$ ), hybridizing probe was detected using an antidigoxigenin alkaline phosphatase-conjugated antibody (Boehringer Mannheim).

\section{Results}

\section{Characterization of a cDNA clone encoding a myomodulin} precursor

Screening a buccal ganglion cDNA library with six pooled oligonucleotides designed from the sequence of myomodulin A (see Materials and Methods) resulted in the isolation of four candidate clones. Restriction enzyme and sequence analyses indicated that all four clones contained related, overlapping inserts. An $E c o$ R I digestion of the largest insert produced three fragments $\sim 750, \sim 550$, and $\sim 120 \mathrm{bp}$ in length (designated pMM12, pMM13, and pMM22, respectively, in Fig. 1). The order and orientation of these fragments within the $\lambda$ clone were deduced using the linker positions, polyA tail, and open reading frame (ORF) as cues. This arrangement was confirmed by cloning and sequencing a PCR product (Fig. 1, pMM21) generated using primers (Fig. 1, PMS009 and PMS004) flanking the two internal EcoR I sites and the $\lambda$ phage stock isolate $(1 \mu \mathrm{l})$ as template.

The complete phage insert ( $1432 \mathrm{bp}$ ) corresponds to an mRNA that encodes a myomodulin precursor protein 370 amino acids in length (Fig. 2). The assigned translation initiation methionine (Fig. 2, MET) is preceded by 223 nucleotides of $5^{\prime}$ untranslated sequence in which two in-frame stop codons are present. The assigned initiator codon is located within a sequence (CAACCAUG) that agrees closely with the consensus for eukaryotic initiation sites (Kozak, 1983). However, the possibility that the initiation of translation occurs at a second methionine residue (position 5) cannot be ruled out. The ORF is terminated by a UAA stop codon (Fig. 2, asterisk) that is followed by 31 nucleotides exclusive of the polyA tail of $3^{\prime}$ untranslated sequence including a consensus signal (AAUAAA) for polyadenylation (Setzer et al., 1980). Twelve nucleotides separate the polyadenylation signal from the polyA tail. Short $3^{\prime}$ untranslated sequences have been noted in several genes encoding neuropeptides in molluscs (Schaefer et al., 1985; Smit et al., 1988).

\section{Deduced structure of the myomodulin precursor}

The proposed initiator methionine is followed by a sequence of 12 amino acids that could act as a signal peptide, directing 
Figure 1. Restriction maps of fragments derived from a single recombinant buccal ganglion cDNA clone that encodes a myomodulin precursor polyprotein. Open bars denote proposed ORF and thinner lines represent regions corresponding to $5^{\prime}$ and $3^{\prime}$ untranslated sequence. Clones $p M M 13, p M M 22$, and pMM12 were derived from an $E c o$ R I digestion of a $\lambda$ clone insert $\sim 1.3 \mathrm{~kb}$ in length. Two 17-mer PCR primers (denoted PMSOO9 and PMSOO4) were used to generate $p M M 21$ (see Materials and Methods) in order to confirm the position and orientation of two internal EcoR I restriction sites.

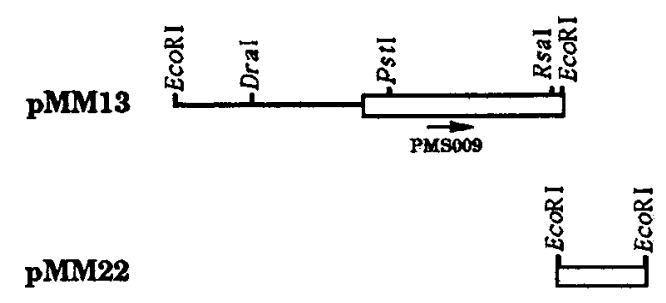

pMM12

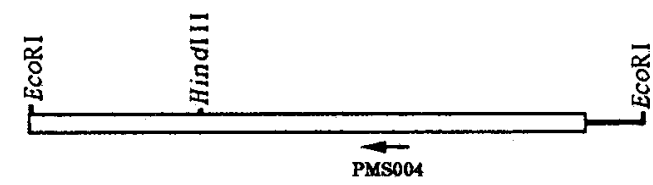

pMM21

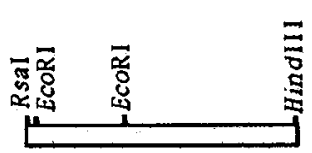

translocation of the nascent myomodulin precursor protein to the endoplasmic reticulum (Walter and Blobel, 1981). This sequence contains several well-conserved features of signal peptide structure (von Heijne, 1988), for example, a hydrophobic core rich in apolar residues ( 3 leucines, 2 alanines, 1 phenylalanine). Cleavage of this sequence from the prohormone may occur following the alanine residue in position 13 (Fig. 2, downward arrowhead). This proposed site of signal peptidase cleavage is based upon amino acid patterns observed in eukaryotic signal peptides (Perlman and Halvorson, 1983; von Heijne, 1986): (1) it conforms to the " $(-3,-1)$ rule" since the amino acids in these positions, valine and alanine (denoted -3 and -1 , respectively, in Fig. 2) are both apolar; (2) the -2 position is occupied by the bulkier residue phenylalanine; and (3) a proline is present in the -6 position. The predicted signal peptide is very short (13 residues) and further experiments will be required to clarify whether signal peptidase cleavage actually occurs at this position or at a site more distal from the amino terminus (e.g., $\mathrm{Ala}^{25} \mathrm{Ala}^{26} \mathrm{Ala}^{27}$ ).

The remaining prohormone, 357 residues in length, contains three separate regions from which myomodulin-related peptides may be cleaved (Figs. 2, 3). Two of these peptides, myomodulin $\mathrm{B}$ and myomodulin $\mathrm{H}$, are located in the amino-terminal half of the precursor. Dibasic endoproteolytic cleavage sites flank this region and a single arginine residue is present between the two peptides (position 62). The single octapeptide present on the precursor, myomodulin $\mathrm{B}$, has been purified from neural elements in the ARC muscle (Cropper et al., 1991), indicating that cleavage takes place at this site. The sequence in the vicinity of this arginine conforms to each of four rules and five tendencies that were compiled from comparisons of known monobasic processing sites in peptide precursors (Devi, 1991). Processing at specific monobasic sites occurs in several precursors for molluscan regulatory peptides (Mahon et al., 1985; Newcomb and Scheller, 1987; Linacre et al., 1990).

The amino-terminal peptide-coding portion of the myomodulin precursor is followed by a sequence of 118 amino acids (positions 73-190) that does not contain myomodulin-related peptides. This region is very hydrophilic, containing 39 charged residues. Acidic amino acids predominate, accounting for 34 of the residues ( 20 glutamic acid and 14 aspartic acid) in this part of the precursor. A pair of arginine residues (positions 126 and
127) provides an additional potential site of endoproteolytic cleavage.

The carboxyl-terminal half of the precursor consists primarily of myomodulin-related peptides, all of which are flanked by dibasic Lys-Arg cleavage sites. Two such peptides, myomodulin I and myomodulin D (Figs. 2, 3), occur in tandem (Fig. 3B), separated from the remainder of the carboxyl-terminal portion of the precursor by a 25 residue acidic region that contains six glutamic acid and six aspartic acid residues. A pair of lysines (positions 222 and 223) occurs within this sequence. This region is followed by a single copy of myomodulin $\mathrm{G}$ and 10 contiguous copies of myomodulin A. As is the case for all of the myomodulin-related peptides, a glycine residue precedes each dibasic cleavage site. This glycine is likely to contribute to the carboxylterminal amide group during the posttranslational processing of these peptides (Loh and Gainer, 1983). Carboxyl-terminal amidation is required for bioactivity of myomodulin-related peptides (Cropper et al., 1988, 1991).

The 10 copies of myomodulin A are followed by a short (six residues) acidic region and a single copy of myomodulin $F$. The carboxyl-terminal Lys-Arg of myomodulin F is followed by three amino acids. An extension of at least three amino acids on the carboxyl-terminal side of the Lys-Arg doublet may be required for efficient endoprotease substrate recognition (Brakch et al., 1989).

\section{The myomodulin-related peptides}

A total of seven different myomodulin-related peptides are present on the myomodulin precursor polypeptide (Fig. $3 A$ ). Each peptide occurs in a single copy except myomodulin $A$, which is found in 10 contiguous copies. Each of the myomodulin-related peptides shares a common carboxyl-terminal Met-Leu-Arg-Leu$\mathrm{NH}_{2}$ sequence with the exception of myomodulin $\mathrm{B}$, in which methionine substitutes for leucine in the -3 position. A serine residue predominates in the -5 position; however, the two peptides located in the amino-terminal peptide-coding region of the precursor (myomodulin $\mathrm{B}$ and myomodulin $\mathrm{H}$ ) have basic residues (arginine and histidine, respectively) in this position. The -6 position tends to be hydrophobic, with leucine predominating (five of seven peptides), and the amino acids in the -7 position tend to be small and polar. 
AGAGAAGTTGTTCA $-223$

CTTTTCAAACTTTTGGGAACGGGGCAGCCAGCAGCGAGGAACTTCTTGCGTACGTCAAAGGACGAGGAACTTTTAAAGA

MET GL Val Tyr Met Leu Leu

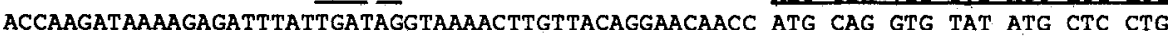
$8 \quad-3 \quad-17$ Pro Leu Ala Val phe Ala Ser Leu Thr Tyr Gln Gly Ala Cys Glu Giu Thr Ala Ala Ala CCG CTT GCT GTC TTT GCC TCT CTG ACC TAC CAG GGT GCC TGT GAA GAA ACT GCT GCA GCT 28

Gln Thr Ser Ser Asp Ala Ser Thr Ser Ser Ala Ser Ser Glu His Ala Glu Asn Glu Leu CAA ACC AGC AGC GAT GCA TCA ACT TCT TCT GCT TCT TCG GAG CAC GCC GAG AAC GAG CTG

48 Ser Arg Ala Lys_Arg Gly Ser Tyr Arg Met Met Arg Leu Gly Aro Gly Leu His Met Leu TCA CGA GCA AAA CGA GGC AGT TAC AGA ATG ATG AGA CTT GGC AGA GGT TTG CAC ATG CTC

Arg Leu Gly Lys Are Gly Gly Pro Val Glu Pro Glu ser Glu Glu Asn Leu glu Thr Leu AGA CTG GGG AAA AGG GGA GGG CCC GTC GAG CCT GAG AGC GAG GAA AAC CTG GAA ACC CTT

Leu Asn Leu Leu Gln Gly Tyr Tyr Ser Asp Val Pro Glu Tyr Pro Ser Glu Phe Asp Asp TTG AAC TTA TTG CAA GGT TAC TAC AGT GAT GTA CCG GAG TAT CCA TCT GAA TTC GAC GAC

108

Thr Asp Leu Ala Tyr Pro Tyr Glu Glu Tyr Asp Ala pro Ala His Pro Arg Tyr Aro Aro ACT GAT TTG GCC TAC CCA TAC GAA GAA TAC GAC GCC CCC GCC CAC CCG AGA TAC CGG AGA

128

Ser Thr Pro Pro Thr Asp Gly Val Val Ala Pro Asp Val Leu Gln Lys Gly Ser Ser Glu TCT ACA CCT CCT ACA GAC GGC GTG GTG GCA CCA GAC GTG CTC CAG AAG GGA AGT TCT GAA

148

Phe Glu Asp Phe Gly Asp Ser Gln Leu Asp Glu Ser Asp Glu Gly Tyr Tyr Gly Tyr Asp TTC GAA GAC TTT GGT GAT TCC CAG TTG GAC GAA AGT GAT GAA GGT TAC TAT GGT TAC GAC

168

Pro Glu Asn Tyr Leu Tyr Gly Asp Phe Glu Asp Tyr Leu Glu Pro Glu Glu Gly Gly Leu CCT GAA AAC TAT TTG TAT GGC GAT TTT GAA GAT TAC TTG GAA CCA GAA GAA GGA GGA CTT

\section{8}

Gly Glu Glu Lys Arg Ser Leu Ser Met Leu Arg Leu Gly Lys Arg Gly Leu Ser Met Leu GGA GAA GAG AAA AGA AGT CTG TCT ATG CTG CGA TTG GGA AAA CGA GGA CTG TCT ATG CTG

208

Arg Leu Gly Lys Aro Glu Gly Glu Glu Gly Asp Glu Met Asp Lys Iys Gln Asp Glu Ser AGA CTG GGA AAG AGA GAG GGG GAA GAA GGG GAT GAA ATG GAC AAG AAA CAA GAC GAA AGC

228

Leu Asn Asp Ala phe Glu Asn Asp Asp Ile Iys Arg Thr Leu ser Met Leu Arg Leu Gly TTG AAC GAC GCT TTC GAA AAT GAT GAT ATC AAG AGA ACC CTC ICA ATG CTT CGT CTC GGC

$248 \quad A \quad \lambda$

Ius Arg Pro Met ser Met Leu Arg Leu Gly Lus Arg Pro Met Ser Met Leu Arg Leu Gly AAA CGA CCA ATG AGC ATg CTT AGA TTA GGA AAA CGg CCA ATG AGC ATG CTG CGT CTT GGA

$268 \lambda \lambda \quad \lambda$

Ivs Arg Pro Met Ser Met Leu Arg Leu Gly Lys Arg Pro Met Ser Met Leu Arg Leu Gly AAG CGA CCA ATG AGT ATG TTG CGT CTC GGA AAG CGA CCA ATG AGT ATG CTC CGA CTT GGA

$288 \lambda \lambda \quad \lambda$

Iys Arg Pro Met Ser Met Leu Arg Leu Gly Lys Aro Pro Met ser Met Leu Arg Leu Gly AAG CGA CCA ATG AGC ATG CTT CGG CTC GGA AAA CGA CCA ATG AGC ATC CTC ACA CTG CCA

3082

$\boldsymbol{A}$

Lus Arg Pro Met Ser Met Leu Arg Leu Gly Lvs Aro pro Met Ser Met Leu Arg Leu Gly AAg CGg CCA ATG AGC ATG TTG CGC CTT GGA AAA CGA CCA ATG AGC ATG CTG CGT TTG GGG

$328 \quad \mathrm{~A}$

Lys Arg Pro Met Ser Met Leu Arg Leu Gly Lys Arg Pro Met Ser Met Leu Arg Leu Gly AAA CGA CCA ATG AGC ATg CTC CGT CTG GGA AAg CGg CCA ATg AGT ATG TTG CGC CTA GGC

348 $\mathbf{T}$

Lys Arg Asp Asp Asp Glu Lys Glu Iys Lys Ser Leu Asn Met Ieu Arg Leu Giy Iys Aro AAA CGT GAT GAC GAT GAA AAG GAA AAG AAA TCT TTG AAC ATG TTA CGG CTC GGC AAA CGG 370

Ser Thr Gln *

TCG ACA CAG TAA TTTCTTAGCAAGTMTMMgTATAATACAAGA $(n)$
Figure 2. Nucleotide sequence of a cDNA clone encoding a myomodulin precursor protein. The predicted amino acid sequence of a myomodulin precursor polypeptide is shown above the nucleic acid sequence. Numbers below the nucleotide sequence and above the amino acid sequence denote positions relative to the initiator methionine (MET) residue. Two in-frame stop codons in the $5^{\prime}$ untranslated region are overlined. Mono- and dibasic potential sites of endopeptidase cleavage are $u n$ derlined. Boldface letters above the amino acid sequence refer to myomodulin-related peptides that could potentially be processed from the precursor (tabulated in Fig. 3). The amino acids proposed to constitute the signal sequence are underlined. Downward arrowhead indicates proposed site of signal peptidase cleavage. Upward arrowhead denotes site of intron/exon boundary. The stop codon (TAA) is indicated by an asterisk and the consensus polyadenylation signal is shown in boldface. 


\section{A Myomodulin-related Peptides}

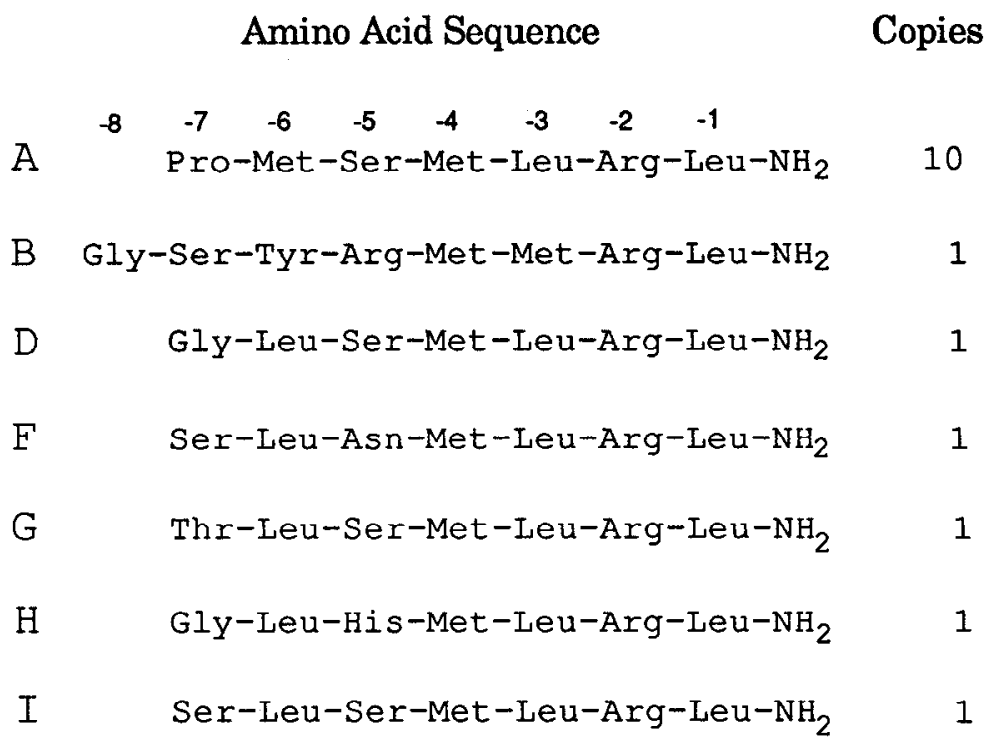

Figure 3. The myomodulin-related peptides and precursor organization. $A$, Tabulation of sequences and copy numbers of peptides potentially processed from the myomodulin precursor protein. A glycine residue present at the carboxyl terminal of each peptide in the precursor is postulated to act as a donor of an amide group. Designation of peptides corresponds to that in Figure 2. Note that endoproteolytic cleavage at a monobasic (Arg) residue would be required to generate the octapeptide, myomodulin B. $B$, Schematic structure of the predicted myomodulin precursor polypeptide. The proposed signal peptide $(S)$ region is cross-hatched. Letters denoting myomodulin-related peptides correspond to designations in Figures 2 and $3 A$. Shaded regions represent charged spacer regions. Certain potential cleavage sites referred to in the text are indicated $\left(R, \mathrm{Arg}^{62} ; R R, \mathrm{Arg}^{126}-\right.$ $\operatorname{Arg}^{127} ; K K$, Lys $^{222}-\operatorname{Lys}^{223}$ and Lys ${ }^{356}$ Lys $^{357}$ ). All other paired vertical lines denote Lys-Arg cleavage sites.

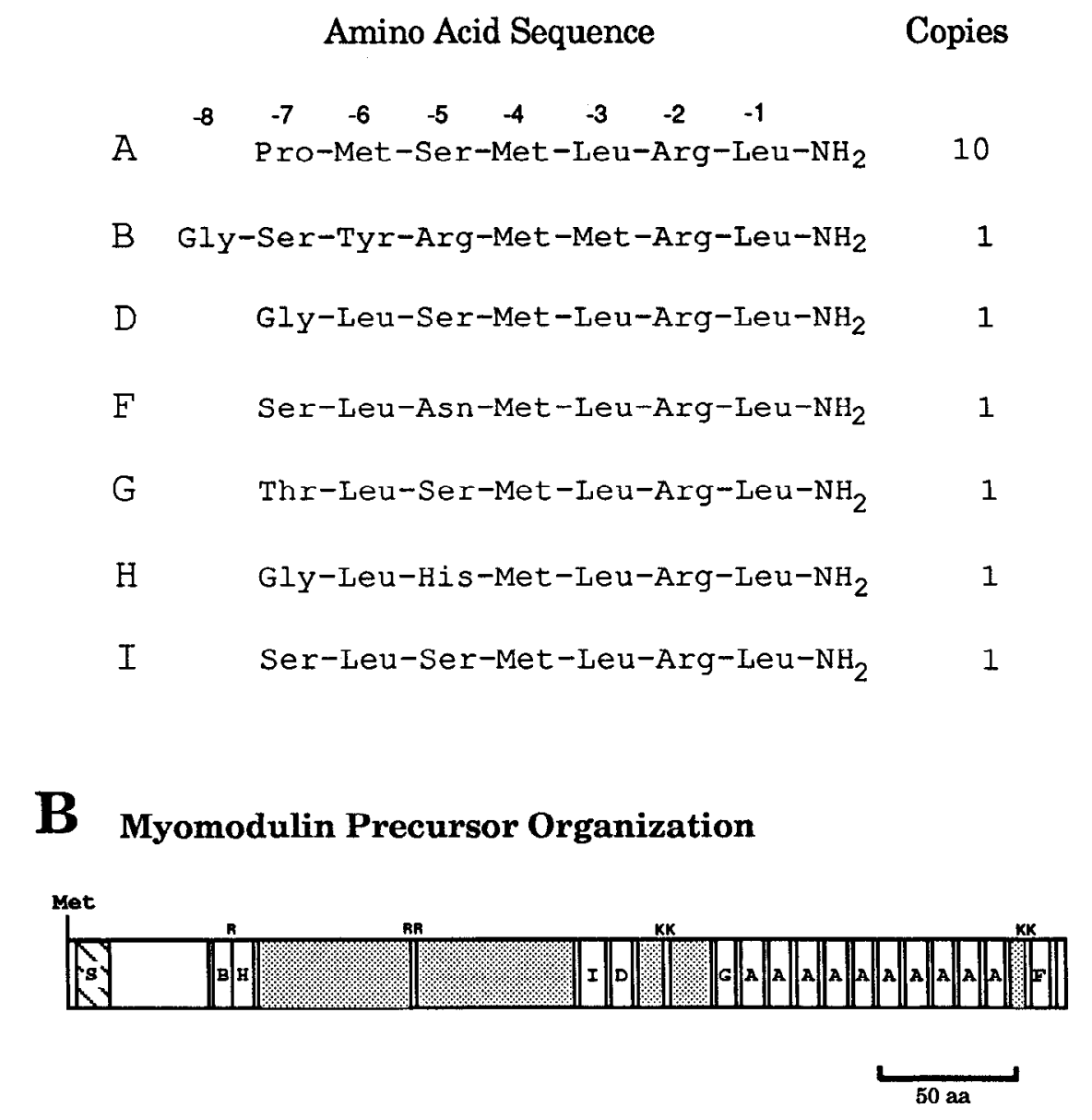

\section{Organization of the myomodulin gene}

Myomodulin gene organization was initially examined with genomic blotting experiments (Fig. 4). Genomic DNA was isolated from the ovotestis of a single Aplysia specimen, digested to completion with various restriction endonucleases, and probed with insert DNA from pMM13 (Fig. 1; $\sim 550 \mathrm{bp}$ ). This probe corresponds to the entire $5^{\prime}$ untranslated region and encodes the 104 amino-terminal residues of the precursor peptide. With the exception of $P s t \mathrm{I}$, there are no restriction sites for the enzymes tested within the sequence of the probe (see Fig. 1). This probe hybridized to multiple bands in each lane, indicating that the Aplysia genome may contain additional genes with substantial homology to this myomodulin clone. The presence of an intervening sequence within this gene could also contribute to such a pattern of hybridization.

In order to examine the myomodulin gene directly, a genomic clone was isolated from a size-selected $[\sim 2.4$ kilobase $(\mathrm{kb})]$ library constructed from a Sac I digest of genomic DNA. Sequence and restriction analyses of this clone showed it to be colinear with much of the cDNA clone, including the $3^{\prime}$ untranslated region and the region encoding the myomodulinrelated peptides (Fig. 5). However, the sequence of the genomic clone diverges from that of the CDNA at a point within the coding region, interrupting the codon for glycine in position 19 of the precursor (Fig. 5; see also Fig. 2, upward arrowhead). The sequence of the genomic clone in this region (TTTGCAGG) corresponds to a consensus $3^{\prime}$ intron/exon splice sequence (Fig. 5; see Padgett et al., 1986). It appears, therefore, that the myomodulin gene contains at least one intron that separates an exon encoding the myomodulin-related peptides from more $5^{\prime}$ portions of the gene.

Restriction mapping indicates that the genomic clone extends approximately $1 \mathrm{~kb}$ in the $5^{\prime}$ direction from the proposed intron/ exon boundary (Fig. 5). Probes homologous to cDNA sequences $5^{\prime}$ from this point of divergence failed to hybridize to the genomic clone, indicating that the intervening sequence in the gene is at least $1 \mathrm{~kb}$ in length. The organization of the $5^{\prime}$ region of the gene has not been further studied. Large intervening sequences are present in several genes encoding invertebrate regulatory peptides (Nambu et al., 1983; Schneider and Taghert, 1990; Wickham and DesGroseillers, 1991), where they often occur between regions encoding specific functional domains of the precursor (Taussig et al., 1984; Taussig and Scheller, 1986). In the case of the myomodulin gene, an intervening sequence appears to lie between the region that encodes the signal sequence and the neuropeptide-encoding exon (see also Saunders et al., 1992).

\section{Myomodulin gene expression}

RNA blot hybridization was initially used to assess expression of the myomodulin gene. PolyA ${ }^{+}$RNA was isolated from $A p l y$ - 

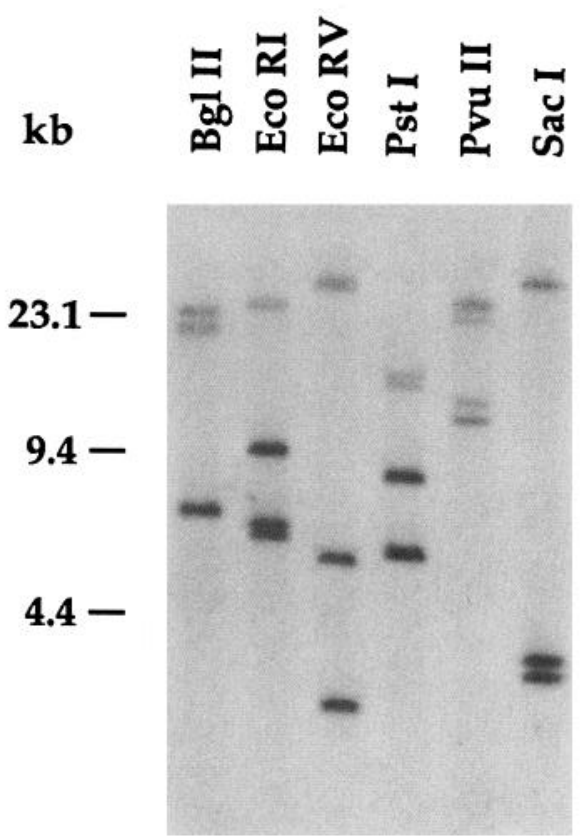

Figure 4. Genomic DNA blot analysis of myomodulin clone: Southern blot of DNA isolated from ovotestis of a single Aplysia specimen. DNA $(10 \mu \mathrm{g} /$ lane) was digested to completion with the restriction enzymes shown for each lane, fractionated on a $0.8 \%$ agarose gel, denatured, blotted onto nylon membrane, and hybridized to the EcoR I insert from pMM13 (see Fig. 1) ${ }^{32} \mathrm{P}$-labeled by random priming. Multiple hybridizing bands were observed within each digest. The size standard was a Hind III digest of wild-type $\lambda$.

sia tissues, size fractionated, transferred to nylon membrane, and probed with labeled insert from pMM13. Exposure of blots (overnight) showed that myomodulin expression occurs in a tissue-specific manner (Fig. 6A). While no hybridization was detected with ovotestis RNA, a single dominant hybridizing band was present in neural RNA. The length of this transcript $(\sim 1.4 \mathrm{~kb})$ indicates that the cDNA clone isolated in this study

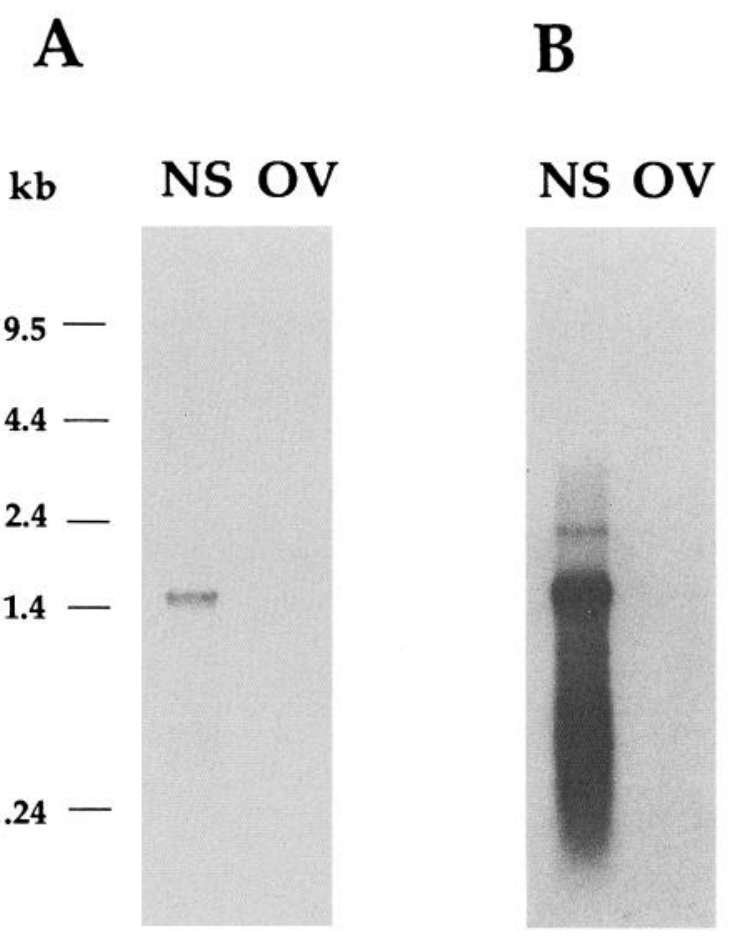

Figure 6. RNA gel blot analysis of myomodulin gene expression. PolyA + RNAs $(5 \mu \mathrm{g})$ extracted from the nervous system $(N S$; pooled central ganglia) and the ovotestis $(\mathrm{OV})$ were fractionated on a denaturing gel, transferred to nylon membrane, and probed with the $E c o \mathrm{R}$ I insert from clone pMM13 (see Fig. 1) ${ }^{32} \mathrm{P}$-labeled by random priming. $A$, Overnight exposure of the blot revealed hybridization to an $\sim 1.4 \mathrm{~kb}$ transcript in the nervous system, but not in the ovotestis. $B$, With longer exposures of the blot ( $7 \mathrm{~d}$ ), numerous additional bands were noted in the nervous system, including one approximately $2.4 \mathrm{~kb}$ in length. RNA molecular weight markers (Bethesda Research Labs) were used as size standards.

(Fig. 2) is a nearly complete copy of the most prominent myomodulin mRNA species in the nervous system. Longer autoradiographic exposure ( $7 \mathrm{~d})$ of Northern blots revealed additional hybridizing bands, including one approximately $2.4 \mathrm{~kb}$

\section{Myomodulin cDNA Clone}

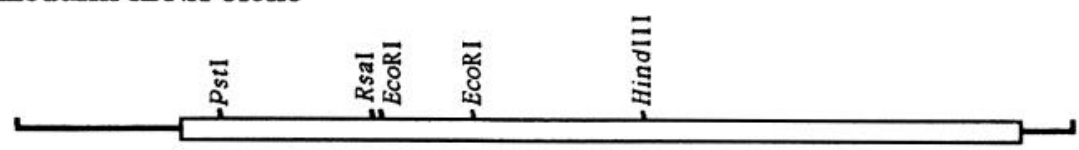

\section{Myomodulin Genomic Clone}

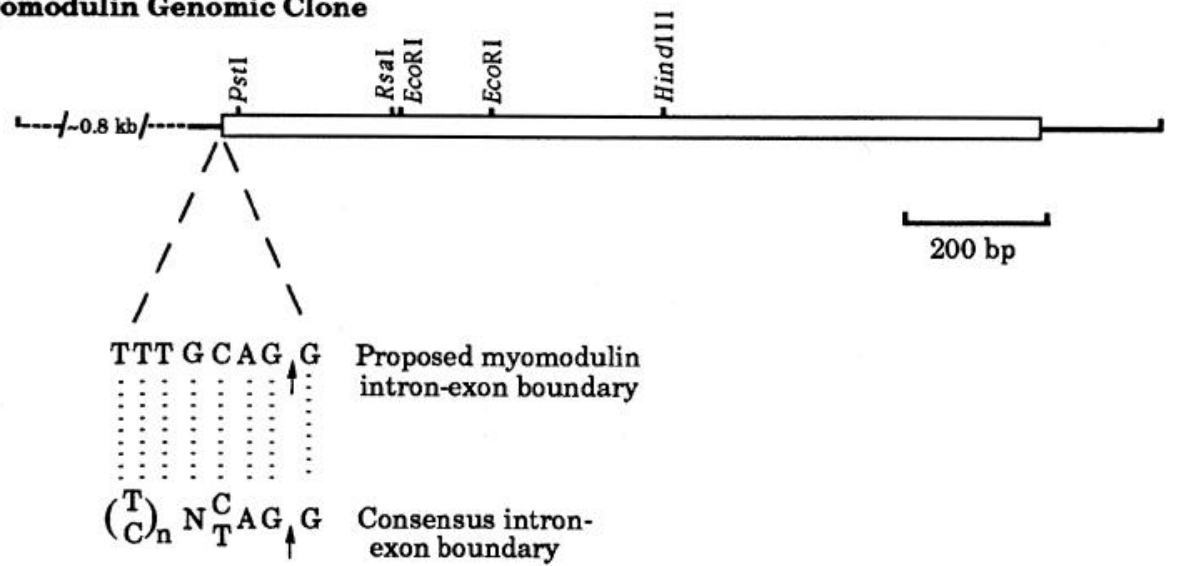

Figure 5. Comparison of restriction maps of myomodulin cDNA and genomic clones. Open bar indicates ORF; dark lines correspond to untranslated regions. Dashed line in genomic clone denotes portion of the clone that has not been completely characterized. The cDNA and genomic sequences are colinear throughout much of their extent, but they diverge at a point $\left(5^{\prime}\right.$ from the Pst I site; see Fig. 2, upward arrowhead) that is within the ORF. The nucleotide sequence found in the genomic clone at this point is shown below and compared to a consensus $3^{\prime}$ intron-exon boundary (Padgett et al., 1986). 
Figure 7. Expression of the myomodulin precursor mRNA occurs in specific cells in the Aplysia nervous system: in situ hybridization of a digoxigeninUTP-labeled cRNA probe generated from a $386 \mathrm{bp}$ Rsa I Hind III fragment from the coding region of the myomodulin cDNA (corresponding to the bases $294-683$ of Fig. 2). Antisense probe hybridized to the cytoplasmic region of specific neuronal somata in the anterior portion of the pedal ganglion $(A)$, the anterior portion of the pleural ganglion $(B)$, and lateral cells in the cerebral ganglion $(C)$. Note signal present in initial segment of neuron in cerebral ganglion (arrow). D, No specific hybridization was observed in the same region of the cerebral ganglion as $C$ with a sensestrand cRNA probe. Scale bar, $100 \mu \mathrm{m}$.
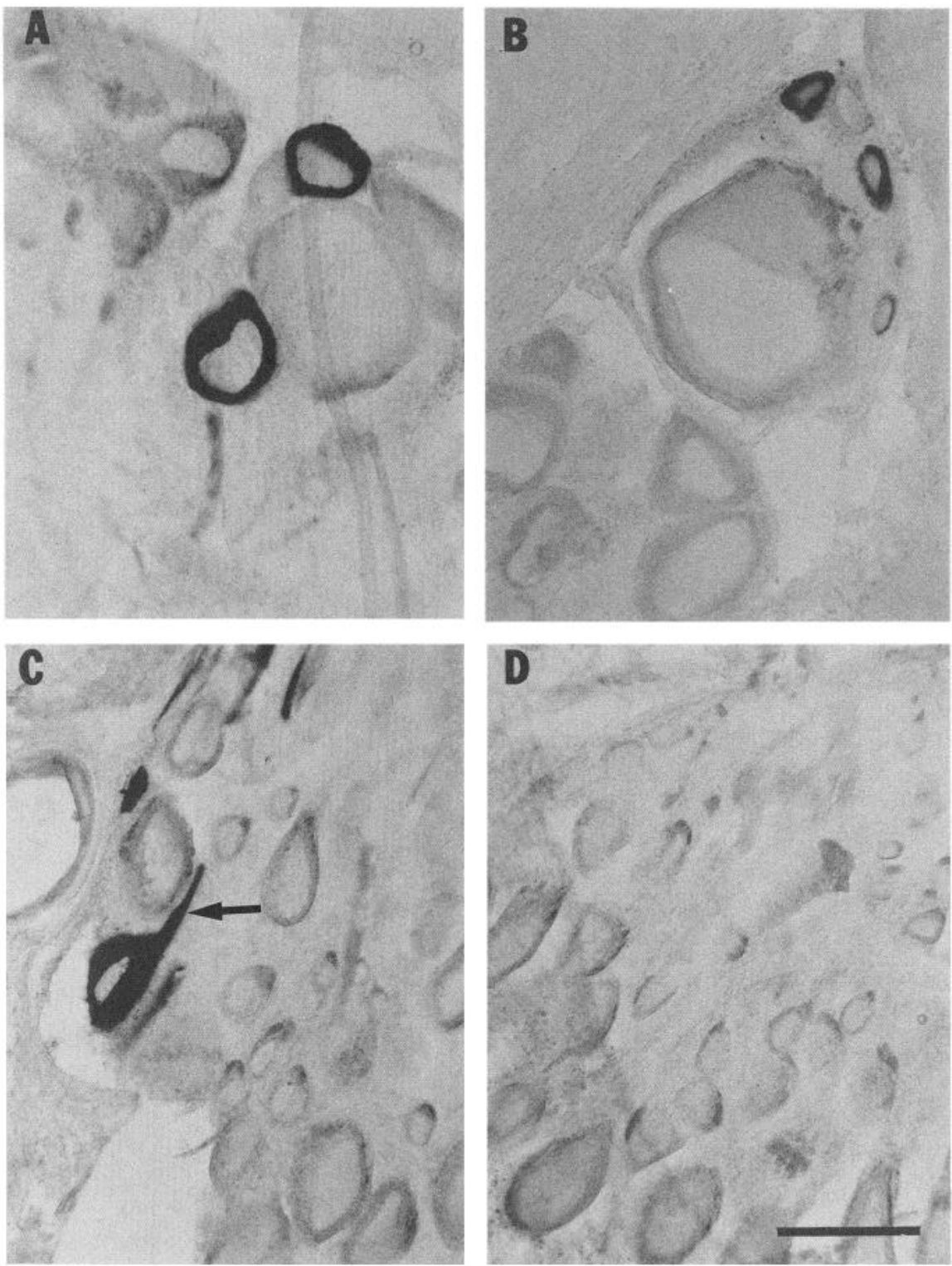

in length (Fig. 6B). These bands could result either from less abundant forms of this myomodulin transcript including incompletely processed precursors or from transcripts of related genes.

Myomodulin gene expression was also investigated using in situ hybridization to histological sections of Aplysia central ganglia. Hybridization of a digoxigenin-labeled antisense probe occurred to specific neurons and cell clusters in each of the ganglia (Fig. $7 A-C$ ). The myomodulin message was localized to the cytoplasmic region of cell somata and was also present in the initial segment of a few cells (Fig. $7 C$, arrow). Probes generated from the complementary (sense) strand failed to hybridize, indicating specificity of transcript detection (Fig. $7 D$ ). These findings are in general agreement with a recent mapping of myomodulin-like immunoreactivity in the Aplysia CNS (Miller et al., 1991a).

\section{Discussion}

In this study, we have isolated and characterized cDNA and genomic clones that encode a precursor for myomodulin-related peptides in Aplysia californica. The organization of the myomodulin gene and the precursor that it encodes presents several potential mechanisms for generating peptide diversity and specificity in neurons.

\section{Myomodulin precursor organization}

The cDNA and genomic clones characterized in this study encode a myomodulin precursor from which multiple distinct but structurally related peptides are likely to be cleaved during posttranslational processing (Loh et al., 1984; Sossin et al., 1989). Two acidic "spacer" domains serve to define three distinct regions in which the myomodulin-related peptides tend to occur in tandem, that is, separated only by Gly-Lys-Arg processing sites (Figs. 2, 3B). Acidic sequences often occur in precursors for neuropeptides, where they are thought to affect processing enzymes or to facilitate packaging into secretory granules via ionic interactions with the basic peptide-containing regions (Noda et al., 1982; Schaefer et al., 1985; Taussig and Scheller, 1986).

Certain unique pairs of basic residues that occur only within the acidic spacer regions (see Fig. $3 B$ ) could provide posttransla- 
tional flexibility of myomodulin precursor processing. The egglaying hormone (ELH) precursor of Aplysia is processed via a series of specific endoproteolytic cleavages, the first of which serves to divide the protein into two polypeptides (Newcomb and Scheller, 1987; Newcomb et al., 1988; see also Linacre et al., 1990). Endopeptidases targeting specific loci (e.g., $\mathrm{Arg}^{126}$ $\mathrm{Arg}^{127}, \mathrm{Lys}^{222}-\mathrm{Lys}^{223}$ ) could similarly partition the myomodulin precursor. Immunohistochemical and autoradiographic data indicate that the peptides derived from the two initial ELH precursor polypeptides are differentially packaged and sorted by the neurosecretory bag cells (Fisher et al., 1988), and that they are targeted to different release sites (Sossin et al., 1990). If such sorting were to occur in cells that express the myomodulins, it could provide a means of segregating certain peptides, for example, the peptides (myomodulins $B$ and $H$ ) present in the amino-terminal half of the precursor. These possibilities could be tested using identified neurons, for example, the widely acting abdominal ganglion interneuron L10, which synthesizes myomodulins A and B (Alevizos et al., 1987; Cropper et al., 1991; Miller et al., 1991a) and exerts numerous central and peripheral actions (Frazier et al., 1967; Koester and Alevizos, 1989).

\section{Myomodulin gene organization}

Genomic blotting experiments (Fig. 4) indicated that the myomodulin gene comprises at least two exons, but left unresolved the possibility that additional related genes could be present. Interpretation of these experiments is rendered difficult by the high degree of polymorphism that appears to be present in regions encoding peptide precursors in Aplysia (Scheller et al., 1982; Nambu et al., 1983; Miller et al., 1993). Furthermore, the pattern of "doublet" bands in genomic blots (see Fig. 4) has been observed to vary among individual specimens (not shown), indicating the presence of allelic variation in the vicinity of the myomodulin gene.

An intron appears to partition the myomodulin gene into at least two domains (Figs. 2, upward arrowhead; 5). All of the cDNA clones examined were colinear with the genomic clone in the region corresponding to the myomodulin-related peptides (Fig. 5), indicating that alternative RNA splicing mechanisms are not used to produce differential expression of these peptides (cf. Nawa et al., 1984; Buck et al., 1987). The position of the intron, separating the region encoding the proposed signal peptide from the region encoding the remainder of the precursor, is strikingly similar to the arrangement of the genes encoding Phe-Met-Arg-Phe-amide (FMRFamide) in Aplysia (Taussig and Scheller, 1986) and Lymnaea (Saunders et al., 1991, 1992). This organization is consistent with Gilbert's (1978) hypothesis, in which it is proposed that exons correspond to functional domains of proteins.

Five of the myomodulin-related peptides (myomodulins A, B, D, F, and G) encoded by the clones isolated in this study have been purified from neural elements in the ARC muscle (Cropper et al., 1987b, 1991; Miller et al., 1990). In purification studies, myomodulin $A$ is typically found at approximately sixfold higher concentrations than myomodulin B (Cropper et al., 1991). Such deviations from the precursor stoichiometry (10:1) may simply reflect differences in peptide recovery or they may be due to specificities of peptide processing, sorting, or degradation. The purification of two additional related peptides (myomodulins C and E; see Miller et al., 1990) that are not encoded by the clones indicates the presence of additional myomodulinencoding transcripts. These peptides could be encoded by re- lated genes (see Scheller et al., 1982; Douglass et al., 1984) or by a separate exon within a single gene (see Amara et al., 1982; Saunders et al., 1991, 1992). One hypothetical scenario, that is, that the exon encoding the signal sequence could be spliced to an exon encoding a distinct set of myomodulin-related peptides, was tested by isolating 19 nervous system cDNA clones with a probe homologous to the sequence encoding the signal peptide. All of these clones hybridized to a second probe based upon the most 5 ' sequence of the exon encoding the myomodulin-related peptides (not shown). These results indicate that alternative splicing of an exon encoding this signal sequence to a second peptide-encoding exon does not occur in the nervous system (cf. Saunders et al., 1992); however, a complete characterization of the gene(s) encoding myomodulin-related peptides will require further study.

\section{The myomodulin peptide family}

Members of a peptide family typically exhibit considerable homology in their carboxyl-terminal sequences (e.g., Mahon et al., 1985; Price, 1986). The myomodulin-related peptides encoded by the clones isolated in this study (with the exception of myomodulin B) share the common Met-Leu-Arg-Leu- $\mathrm{NH}_{2}$ carboxyl motif (Fig. $3 A$ ). This sequence is also present in the myomodulin-related peptides isolated from Fusinus (Kobayashi and Muneoka, 1990) and Mytilus (Hirata et al., 1987; see introductory remarks), indicating that it is a conserved feature of peptides that constitute this intraphyletic family (see Price et al., 1987).

Differences in the amino-terminal extensions of peptides are thought to confer variation in susceptibility to enzymatic degradation and/or receptor specificity (see Greenberg, 1983; Cottrell and Davies, 1987). The specific substitution of leucine for methionine, commonly observed within peptide families (Hughes et al., 1975; Price, 1986), occurs at two positions ( -3 and -6 ) in the myomodulin-related peptides. This substitution may serve to expand the spatial or temporal range of peptide action by lessening the likelihood of oxidation (Price, 1986). Alternatively, or in addition, multiple myomodulin receptors with highly specific sensitivities to individual peptides may occur in certain tissues (cf. Brussaard et al., 1991; Kemenes et al., 1992). This possibility is supported by the observation of differences between the effects of myomodulin $A$ and those of myomodulin $B$ on evoked contractions of the ARC muscle (Cropper et al., 1991). It would be of interest to compare further the effects of the myomodulin-related peptides in this system and to extend such comparisons to the myomodulin receptors that are present on neurons (see Rosen et al., 1989; Critz et al., 1989).

The myomodulin-related peptides exhibit a highly specific and widespread pattern of expression in identifiable neurons throughout the CNS of Aplysia (Church and Lloyd, 1991; Miller et al., 1991a). This characterization of the myomodulin gene should facilitate further studies aimed toward determining ontogenetic, physiological, and environmental factors that influence this pattern of expression. It may also contribute to our understanding of the evolutionary and functional relationships that exist among the members of this neuropeptide family.

\section{References}

Alevizos A, Weiss KR, Koester J (1987) Myomodulin: a possible cotransmitter of the cholinergic neuron L10 of Aplysia. Soc Neurosci Abstr 13:1072.

Amara SG, Jonas V, Rosenfeld MG, Ong ES, Evans RM (1982) Alternative RNA processing in calcitonin gene expression generates 
mRNAs encoding different polypeptide products. Nature 298:240 244.

Bishop CA, Wine JJ, Nagy F, O'Shea MR (1987) Physiological consequences of a peptide co-transmitter in a crayfish nerve-muscle preparation. J Neurosci 7:1769-1779.

Brakch N, Boussetta H, Rholam M, Cohen P (1989) Processing endoprotease recognizes a structural feature at the cleavage site of peptide prohormones. J Biol Chem 264:15912-15916.

Brezina V, Evans CG, Kupfermann I, Weiss KR (1991) Modulation of ion currents in the ARC muscle of Aplysia: convergent actions of serotonin, SCPs, and myomodulins. Soc Neurosci Abstr 17:1305.

Brussaard AB, Schluter NCM, Ebberink RHM, Kits KS, Ter Maat A (1991) Discharge induction in molluscan peptidergic cells requires a specific site of autoexcitatory neuropeptides. Neuroscience 39:479491.

Buck LB, Bigelow JM, Axel A (1987) Alternative splicing in individual Aplysia neurons generates neuropeptide diversity. Cell 51:127-133.

Church PJ, Lloyd PE (1991) Expression of diverse neuropeptide cotransmitters by identified motor neurons in Aplysia. J Neurosci 11: 618-625.

Church PJ, Cohen KP, Scott ML, Kirk MD (1991) Peptidergic motoneurons in the buccal ganglia of Aplysia californica: immunocytochemical, morphological, and physiological characterizations. J Comp Physiol [A] 168:323-336.

Clayton DF, Alvarez-Buylla A (1989) In situ hybridization using PEGembedded tissue and riboprobes: increased cellular detail coupled with high sensitivity. J Histochem Cytochem 37:389-393.

Cohen JL, Weiss KR, Kupfermann I (1978) Motor control of buccal muscles in Aplysia. J Neurophysiol 41:157-180.

Cottrell GA, Davies NW (1987) Multiple receptor sites for a molluscan peptide (FMRFamide) and related peptides of Helix. J Physiol (Lond) 382:51-68.

Critz SD, Baxter DA, Byrne JH (1989) Modulatory effects of serotonin, FMRFamide, and myomodulin on the duration of action potentials excitability, and membrane currents in tail sensory neurons of $A$ plysia. J Neurophysiol 66:1912-1926.

Cropper EC, Lloyd PE, Reed W, Tenenbaum R, Kupfermann I, Weiss KR (1987a) Multiple neuropeptides in cholinergic motor neurons of Aplysia: evidence for modulation intrinsic to the motor circuit. Proc Natl Acad Sci USA 84:3486-3490.

Cropper EC, Tenenbaum R, Kolks MAG, Kupfermann I, Weiss KR (1987b) Myomodulin: a bioactive neuropeptide present in an identified cholinergic buccal motor neuron of Aplysia. Proc Natl Acad Sci USA 84:5483-5486.

Cropper EC, Miller MW, Tenenbaum R, Kolks MAG, Kupfermann I, Weiss KR (1988) Structure and action of buccalin: a modulatory neuropeptide localized to an identified small cardioactive peptidecontaining cholinergic motor neuron of Aplysia californica. Proc Nat Acad Sci USA 85:6177-6181.

Cropper EC, Miller MW, Vilim FS, Tenenbaum R, Kupfermann I, Weiss KR (1990a) Buccalin is present in the cholinergic motor neuron B16 of Aplysia and it depresses accessory radula closer muscle contractions evoked by stimulation of B16. Brain Res 512:175-179.

Cropper FC, Kupfermann I, Weiss KR (1990b) Differential fring patterns of the peptide-containing cholinergic motor neurons B15 and B16 during feeding behavior in Aplysia. Brain Res 522:176-179.

Cropper EC, Vilim FS, Alevizos A, Tenenbaum R, Kolks MAG, Rosen S, Kupfermann I, Weiss KR (1991) Structure, bioactivity, and cellular localization of myomodulin B: a novel Aplysia peptide. Peptides 12:683-690.

Devi L (1991) Consensus sequence for processing of peptide precursors at monobasic sites. FEBS Lett 280:4-6.

Douglass J, Civelli O, Herbert E (1984) Polyprotein gene expression: generation of diversity of neuroendocrine peptides. Annu Rev Biochem 53:665-715.

Fisher JM, Sossin W, Newcomb R, Scheller RH (1988) Multiple neuropeptides derived from a common precursor are differentially packaged and transported. Cell 54:813-822.

Frazier WT, Kandel ER, Kupfermann I, Waziri R, Coggeshall RE (1967) Morphological and functional properties of identified neurons in the abdominal ganglion of Aplysia californica. J Neurophysiol 30:12881351.

Gainer H (1988) Mechanisms of neuropeptide precursor processing. Implications for neuropharmacology. In: Neurotransmitters and cortical function. From molecules to mind (Avoli M, Reader TA, Dykes RW, Gloor P, eds), pp 527-546. New York: Plenum.
Gilbert W (1978) Why genes in pieces? Nature 271:501

Greenberg MJ (1983) The responsiveness of molluscan muscles to FMRFamide, its analogs and other neuropeptides. In: Molluscan neuroendocrinology (Lever J, Boer HH, eds), pp 190-196. New York: North Holland.

Herbert E, Birnberg N, Lissitsky J-C, Civelli O, Uhler M (1981) Proopiomelanocortin: a model for the regulation of expression of neuropeptides in pituitary and brain. Neurosci Commun 1:16-27.

Hirata T, Kubota I, Takabatake I, Kawahara A, Shimamoto N, Muneoka Y (1987) Catch-relaxing peptide isolated from Mytilus pedal ganglia. Brain Res 422:374-376.

Hirata T, Kubota I, Imada M, Muneoka Y (1989) Pharmacology of relaxing response of Mytilus smooth muscle to the catch-relaxing peptide. Comp Biochem Physiol [C] 92:289-295.

Hughes J, Smith TW, Kosterlitz HW, Fothergill LA, Morgan BA, Morris HR (1975) Identification of two related pentapeptides from the brain with potent opaite agonist activity. Nature 258:577-580.

Jan LY, Jan YN (1982) Peptidergic transmission in sympathetic ganglia of the frog. J Physiol (Lond) 327:219-246.

Kaczmarek LK, Levitan LB (1987) Neuromodulation. The biochemical control of neuronal excitability. New York: Oxford UP.

Kemenes G, S-Rozsa K, Stefano G, Carpenter DO (1992) Distinct receptors for leu- and met-enkephalin on the metacerebral giant cell of Aplysia. Cell Mol Neurobiol 12:107-119.

Kobayashi M, Muneoka Y (1990) Structure and action of molluscan neuropeptides. Zool Sci 7:801-814.

Koester J, Alevizos A (1989) Innervation of the kidney of Aplysia by L10, the LUQ cells, and an identified peripheral motoneuron. J Neurosci 9:4078-4088.

Kozak M (1983) Compilation and analysis of sequences upstream from the translational start site in eukaryotic mRNAs. Nucleic Acids Res 12:857-872.

Kupfermann I (1979) Modulatory actions of neurotransmitters. Annu Rev Neurosci 2:447-465.

Linacre A, Kellett E, Saunders S, Bright K, Benjamin PR, Burke JF (1990) Cardioactive neuropeptide Phe-Met-Arg-Phe- $\mathrm{NH}_{2}$ (FMRFamide) and novel related peptides are encoded in multiple copies by a single gene in the snail Lymnaea stagnalis. J Neurosci $10: 412-419$

Lloyd PE (1988) Fast axonal transport of modulatory neuropeptides from central ganglia to components of the feeding system in Aplysia. J Neurosci 8:3507-3514.

Lloyd PE, Kupfermann I, Weiss KR (1984) Evidence for parallel actions of a molluscan neuropeptide and serotonin in mediating arousal in Aplysia. Proc Natl Acad Sci USA 81:2934-2937.

Loh YP, Gainer H (1983) Biosynthesis and processing of neuropeptides. In: Brain peptides (Krieger DT, Brownstein MJ, Martin JB, eds), pp 79-116. New York: Wiley.

Loh YP, Brownstein MJ, Gainer H (1984) Proteolysis in neuropeptide processing and other neural functions. Annu Rev Neurosci 7:189222.

Mahon AC, Lloyd PE, Weiss KR, Kupfermann I, Scheller RH (1985) The small cardioactive peptides A and B of Aplysia are derived from a common precursor molecule. Proc Natl Acad Sci USA 82:39253929.

Marder E (1988) Modulating a neuronal network. Nature 335:296297.

Miller MW, Vilim FS, Cropper EC, Alevizos A, Tenenbaum R, Karagogeos D, Kupfermann I, Weiss KR (1990) Structure and distribution of myomodulin-related neuropeptides in Aplysia. Soc Neurosci Abstr 16:307.

Miller MW, Alevizos A, Cropper EC, Vilim FS, Karagogeos D, Kupfermann I, Weiss KR (199 la) Localization of myomodulin-like immunoreactivity in the central nervous system and peripheral tissues of Aplysia californica. J Comp Neurol 314:627-644.

Miller MW, Stamm S, Cropper EC, Vilim FS, Beushausen S, Brosius J, Kupfermann I, Weiss KR (1991b) Characterization of a cDNA clone encoding multiple myomodulin-related neuropeptides in Aplysia. Soc Neurosci Abstr 17:1305.

Miller MW, Beushausen S, Cropper EC, Eisinger K, Stamm S, Vilim FS, Vitek A, Zajc A, Kupfermann I, Brosius J, Weiss KR (1993) The buccalin-related neuropeptides: isolation and characterization of an Aplysia cDNA clone encoding a family of peptide cotransmitters. J Neurosci 13:3346-3357.

Nambu JR, Taussig R, Mahon AC, Scheller RH (1983) Gene isolation 
with cDNA probes from identified neurons: neuropeptide modulators of cardiovascular physiology. Cell 35:47-56.

Nawa H, Kotani H, Nakanishi S (1984) Tissue specific generation of two preprotachykinin mRNA from one gene by alternative RNA splicing. Nature 312:729-734.

Newcomb R, Scheller RH (1987) Proteolytic processing of the Aplysia egg-laying hormone and R3-R14 neuropeptide precursors. J Neurosci 7:854-863.

Newcomb R, Fisher JM, Scheller RH (1988) Processing of the egglaying hormone (ELH) precursor in the bag cell neurons of Aplysia. J Biol Chem 263:12514-12521.

Noda M, Furutani Y, Takahashi H, Toyosato $M$, Hirose $T$, Inayama S, Nakanishi S, Numa S (1982) Cloning and sequence analysis of cDNA for bovine adrenal preproenkephalin. Nature 295:202-206.

O'Shea M, Adams ME, Bishop C, Witten J, Worden MK (1985) Model peptidergic systems at the insect neuromuscular junction. Peptides 6:417-424.

Padgett RA, Grabowski PJ, Konarska M, Seiler S, Sharp PA (1986) Splicing of messenger RNA precursors. Annu Rev Biochem 55:11191150.

Perlman D, Halvorson HO (1983) A putative signal peptidase recognition site and sequence in eukaryotic and prokaryotic signal peptides. J Mol Biol 167:391-409.

Price DA (1986) Evolution of a molluscan cardioregulatory neuropeptide. Am Zool 26:1007-1015.

Price DA, Davies NW, Doble KE, Greenberg MJ (1987) The variety and distribution of the FMRFamide-related peptides in molluscs. Zool Sci 4:395-410.

Probst WC, Cropper EC, Hooper SL, Kupfermann I, Weiss KR (1992) Convergent peptidergic phosphorylation of proteins in the ARC muscle of Aplysia. Soc Neurosci Abstr 18:1104.

Richmond JE, Bulloch AGM, Lukowiak K (1986) Peptidergic modulation of a neuromuscular junction in Aplysia: bioactivity and immunocytochemistry. Brain Res 370:159-164.

Rosen SC, Susswein AJ, Cropper EC, Weiss KR, Kupfermann I (1989) Selective modulation of spike duration by serotonin and the neuropeptides FMRFamide, $\mathrm{SCP}_{\mathrm{B}}$, buccalin and myomodulin in different classes of mechanoafferent neurons in the cerebral ganglion of Aplysia. J Neurosci 9:390-402.

Sambrook J, Fritsch EF, Maniatis T (1989) Molecular cloning: a laboratory manual. Cold Spring Harbor, NY: Cold Spring Harbor Laboratory.

Sanger F, Nicklen S, Coulson AR (1977) DNA sequencing with chainterminating inhibitors. Proc Natl Acad Sci USA 74:5463-5467.

Saunders SE, Bright K, Kellett E, Benjamin PR, Burke JF (1991) Neuropeptides Gly-Asp-Pro-Phe-Leu-Arg-Phe-amide(GDPFLRFamide) and Ser-Asp-Pro-Phe-Leu-Arg-Phe-amide (SDPFLRFamide) are encoded by an exon $3^{\prime}$ to Phe-Met-Arg-Phe- $\mathrm{NH}_{2}$ in the snail Lymnaea stagnalis. J Neurosci 11:740-745.
Saunders SE, Kellett E, Bright K, Benjamin PR, Burke JF (1992) Cellspecific alternative RNA splicing of an FMRFamide genc transcript in the brain. $\mathbf{J}$ Neurosci 12:1033-1039.

Schaefer M, Picciotto MR, Kreiner T, Kaldany R-R, Taussig R, Scheller RH (1985) Aplysia neurons express a gene encoding multiple FMRFamide neuropeptides. Cell 41:457-467.

Scheller RH, Jackson JF, McAllister LB, Schwartz JH, Kandel ER, Axel R (1982) A family of genes that codes for ELH, a neuropeptide eliciting a stereotyped pattern of behavior in Aplysia. Cell 28:707719.

Schneider LE, Taghert PH (1990) Organization and expression of the Drosophila Phe-Met-Arg-Phe- $\mathrm{NH}_{2}$ neuropeptide gene. J Biol Chem 265:6890-6895.

Setzer DR, McGrogan M, Nunberg JA, Schimke RT (1980) Size heterogeneity in the $3^{\prime}$ end of dihydrofolate reductase messenger RNAs in mouse cells. Cell 22:361-370.

Smit AB, Vreugdenhil E, Ebberink RHM, Geraerts WPM, Klootwijk J, Joose J (1988) Growth-controlling molluscan neurons produce the precursor of an insulin-related peptide. Nature 331:535-538.

Sossin WS, Fisher JM, Scheller RH (1989) Cellular and molecular biology of neuropeptide processing and packaging. Neuron 2:14071417.

Sossin WS, Sweet-Cordero A, Scheller RH (1990) Dale's hypothesis revisited: different neuropeptides derived from a common prohormone are targeted to different processes. Proc Natl Acad Sci USA 87 $4845-4848$.

Taussig R, Scheller RH (1986) The Aplysia FMRFamide gene encodes sequences related to mammalian brain peptides. DNA 5:453-461.

Taussig R, Picciotto MR, Scheller RH (1984) Two introns define functional domains of a neuropeptide precursor in Aplysia. In: Molecular biology of development, Vol 19 (Davidson EH, Firtel RA, eds), pp 551-560. New York: Liss.

Tiedge $\mathrm{H}$ (1991) The use of UV light as a cross-linking agent for cells and tissue sections in in situ hybridization. DNA Cell Biol 10:143147.

von Heijne $G$ (1986) A new method for predicting signal sequence cleavage sites. Nucleic Acids Res 14:4683-4690.

von Heijne G (1988) Transcending the impenetrable: how proteins come to terms with membranes. Biochim Biophys Acta 947:307-333.

Walter P, Blobel G (1981) Translocation of proteins across the endoplasmic reticulum. II. Signal recognition protein (SRP) mediates the selective binding to microsomal membranes of in-vitro-assemble polysomes synthesizing secretory protein. J Cell Biol 91:551-556.

Wickham L, DesGroseillers L (1991) A bradykinin-like neuropeptide precursor gene is expressed in neuron L5 of Aplysia californica. DNA Cell Biol 10:249-258. 